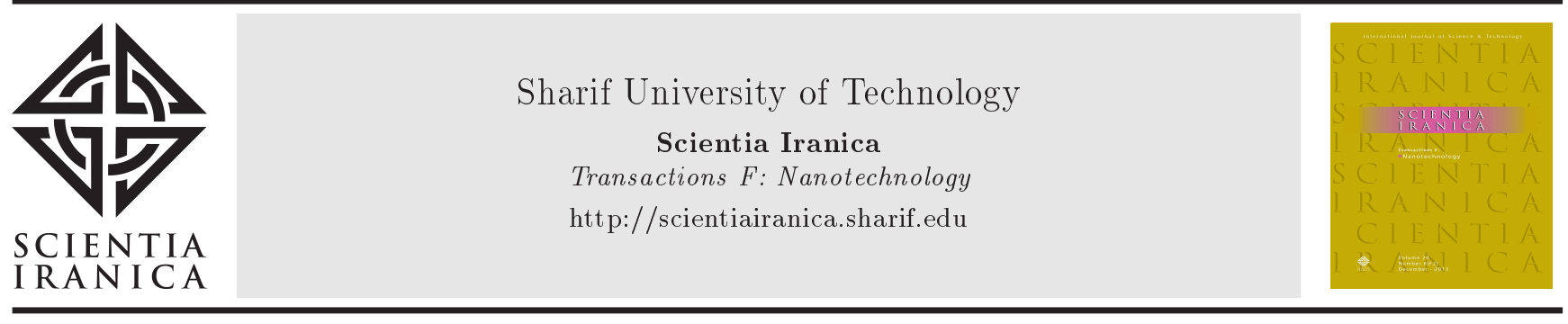

\title{
Microwave aided and plant reduced gold nanoparticles as talented dye degradation catalysts
}

\author{
S. Francis ${ }^{a}$, E.P. Koshy ${ }^{a}$, and B. Mathew ${ }^{b, *}$ \\ a. Department of Chemistry, St. Joseph's College, Moolamattom, Idukki, 685591, Kerala, India. \\ b. School of Chemical Sciences, Mahatma Gandhi University, Kottayam, 686560, Kerala, India. \\ Received 28 January 2018; accepted 22 December 2018
}

\section{KEYWORDS}

Microwave;

Elephantopus scaber;

Gold nanoparticles;

Dye degradation.

\begin{abstract}
Green alternatives prevail over hazardous and expensive pathways of nanoparticle synthesis. This study reports eco-friendly manufacturing of gold nanoparticles by microwave assistance. The water-soluble organic constituents of the tropical herb Elephantopus scaber function as the three-electron donor and the aggregation preventer. XRD spectra certified $f c c$ crystal lattice, and the TEM images supported mixed spherical and triangular geometries of the nanoparticles with an average particle size of $18.97 \pm$ $5.86 \mathrm{~nm}$. Ecological relevance of the gold nanoparticles lies in their ability to degrade methylene blue and methyl orange. The catalytic capacity of the gold nanoparticles is exploited for the reduction of 4-nitrophenol. Large-scale production of gold nanoparticles in an easy manner using renewable sources improves the 'green' significance of the present synthesis.
\end{abstract}

(C) 2019 Sharif University of Technology. All rights reserved.

\section{Introduction}

The beauty of miniature science is put on display by nanotechnology. Biogenic synthesis of metal nanoparticles is the eco-friendly modification of nanoscience. Nanobiotechnology is an umbrella term that encompasses the synthesis, characterization, and exploitation of its biomedical applications [1]. Secondary process on the surface of nanoparticles makes them promising material as low-cost nanocatalysts, value-added products, a commodity for environmental pollution controlling systems, antibacterial coatings, etc. [2]. Plant reduced gold nanoparticles generally have spherical, triangular,

*. Corresponding author. Tel./Fax: +91-481-2731036 E-mail address: srsijofrancis@gmail.com (S. Francis); epkosh@gmail.com (E.P. Koshy); beenamscs@gmail.com (B. Mathew)

doi: $10.24200 /$ sci.2018.50357.1656 and cubical shapes; flavonoid, polyphenol, ascorbic acid, citric acid, and alkaloid contents present in the plant extracts make them captivate reducing and capping agents [3]. Unique physical and chemical characteristics of gold nanoparticles make them suitable for biological and chemical sensing applications [4].

The medicinal plant Elephantopus scaber belongs to the family of sunflower. Healing power of Elephantopus scaber for fevers, diarrohea, ulcers, bronchitis, stomach disorders, and various viral and bacterial infections is well known [5]. The microwave fabrication of stable gold nanoparticles using phytoreducer Elephantopus scaber (E. scaber) is reported here for the first time. The effects of different microwave irradiation times and the amounts of leaf extract on the formation of nanoparticles were studied. UVvisible, FTIR, powder XRD, and TEM-EDAX characterizations were performed on the nanoparticles. The catalytic power of the newly synthesized gold nanoparticles was explored in the degradation of dyes 
methylene blue and methyl orange alone with the chemical reduction of 4-nitrophenol without irradiation of light.

\section{Materials and methods}

Chloroauric acid $\left(\mathrm{HAuCI}_{4} \cdot 3 \mathrm{H}_{2} \mathrm{O}\right)$ was obtained from Sigma Aldrich. Methyl orange, methylene blue, 4nitrophenol, and Sodium borohydride $\left(\mathrm{NaBH}_{4}\right)$ were purchased from Merck India Ltd and were used without further purification. Solutions were prepared in double distilled water.

\subsection{Preparation of the leaf extract}

Fresh and healthy leaves of Elephantopus scaber were gathered from the wild, and aqueous extract was prepared in double distilled water. Then, $5 \mathrm{gm}$ of 2 day air dried leaves were heated for 30 minutes with $100 \mathrm{~mL}$ of distilled water at $40^{\circ} \mathrm{C}$ in a condenser, and the extract is filtered through Whatman No. 1 filter paper.

\subsection{Preparation of gold nanoparticles}

In the present synthesis of gold nanoparticles assisted by microwave, $1 \mathrm{mM} \mathrm{HAuCI}$ and leaf extract were taken in a specific volume ratio in a $250 \mathrm{~mL}$ beaker and mixed well. It was placed in a domestic microwave oven (Sharp R-219T (W), $800 \mathrm{~W}, 2450 \mathrm{MHz}$ ). The formation of gold nanoparticles is visualized through naked eyes as they impart wine-red color to the reaction mixture. The UV-vis. spectra were recorded after different microwave irradiation times. The effect of the amount of leaf extract on absorption maximum was also studied $(9: 1,8: 2$, and $7: 3)$. The gold colloid g3 after microwave irradiation of $1.5 \mathrm{~min}$ was purified by repeated washing and centrifugation using a refrigerated centrifuge (12000 rpm). The powder obtained was dried and used for further analysis and is abbreviated as AuNP-E. scaber.

\subsection{Characterization techniques}

Spectroscopic investigations were done by Shimadzu UV-2450 (UV-vis.), Perkin Elmer spectrum Two (FTIR), and PANalytic X'PERT-PRO X-ray (XRD) spectrometers. Morphology of the gold nanoparticles was obtained through a JEOL JEM-2100 microscope (TEM) equipped with EDAX attachment.

\subsection{Naked eye and optical sensing of dye degradation}

The ability of the synthesized gold nanoparticles to function as catalysts in the degradation of environmentally polluting organic dyes, i.e., methyl orange and methylene blue, was tested without irradiation of light. Then, $2 \mathrm{ml}$ of methyl orange $\left(1 \times 10^{-4}\right.$ $\mathrm{M})$ methylene blue $\left(8 \times 10^{-5} \mathrm{M}\right), 0.5 \mathrm{ml}$ of freshly prepared $0.06 \mathrm{M} \mathrm{NaBH}_{4}$, and $0.5 \mathrm{ml}$ of AuNP-E. scaber $(0.02 \mathrm{mg} / \mathrm{mL})$ were taken in a $3-\mathrm{ml}$ quartz cuvette. For the optical sensing of dye degradation, the UV-vis. spectra of the reaction mixture were recorded periodically at a time interval of 80 seconds. The visual sensing of dye removal is possible through the observation of minute-to-minute color changes of the reaction aliquots. Reaction kinetics was established by scrutinizing a decrease in absorbance at $\lambda_{\max }$ of the respective dye molecules.

\subsection{Hydrogenation of 4-nitrophenol}

The potential of gold nanoparticles to catalyze the hydrogenation of 4-nitrophenol to 4-aminophenol by $\mathrm{NaBH}_{4}$ was examined [6]. 4-nitrophenol $\left(8 \times 10^{-5} \mathrm{M}\right.$, $2 \mathrm{~mL}), \mathrm{NaBH}_{4}(0.06 \mathrm{M}, 0.5 \mathrm{ml})$, and AuNP-E. scaber $(0.02 \mathrm{mg} / \mathrm{mL}, 0.5 \mathrm{ml})$ were taken in a quartz cuvette, and in-situ UV-vis. spectral data were recorded periodically. The progress of the reduction was indicated by the disappearance of the peak at $400 \mathrm{~nm}$ and functioning of the amino product peak in the UV-vis. spectrometer.

\section{Results}

\subsection{Spectroscopic analyses}

The preliminary indication of gold nanoparticles generation was the development of wine-red color in the reaction vessel on microwave irradiation. Microwave heating provided easy, homogeneous [7], and efficient reactions [8] by the rotational movement of water and other biomolecules [9]. The UV-vis. spectrum of gold nanoparticles in the range of 300-700 nm after a different period of microwave irradiation is shown in Figure 1(a). Following the irradiation of $0.5 \mathrm{~min}$, a peak appeared in the UV-vis. spectrum conferred by the optical property SPR. Consequently, an increase in intensity was found as the time duration of irradiation increased to $1.5 \mathrm{~min}\left(\lambda_{\max }=553 \mathrm{~nm}\right)$. The surface plasmon resonance is a prominent spectroscopic property that results from collective and resonant oscillations of free electrons on the surface of gold nanoparticles with the frequency of electromagnetic radiation used [10]. The absorption maximum depends on shape, size, and aggregation state of the nanoparticles [11]. As the amount of leaf extract increased in the experimental compositions 9:1(g1), 8:2(g2), 7:3(g3), $\lambda_{\max }$ shifted to peaks of shorter wavelength at 538 , 530 , and $527 \mathrm{~nm}$, respectively (Figure $1(\mathrm{~b})$ ), as the size of the gold nanoparticles decreased [12]. Gold nanoparticles generally produce optical property SPR in the range of $500-600 \mathrm{~nm} \mathrm{[13].}$

In the synthesis of AuNP-E. scaber, the functioning chemical reaction involved the oxidation of amino $(\mathrm{N}-\mathrm{H})$, hydroxyl $(\mathrm{O}-\mathrm{H})$, and carbonyl $(\mathrm{C}=\mathrm{O})$ functionalities, which are present in leaf components along with the reduction of $\mathrm{Au}^{3+}$ to $\mathrm{Au}^{0}$ [3]. The 


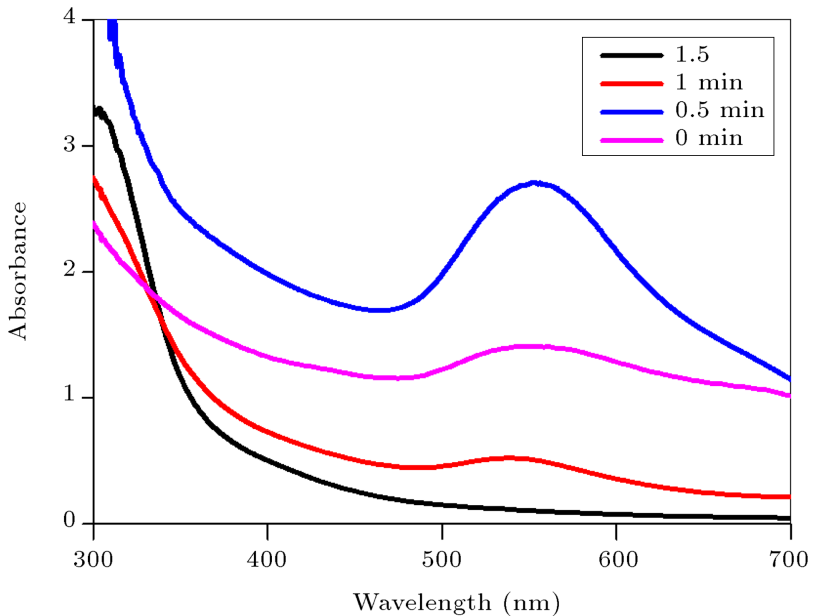

Figure 1(a). UV-vis. spectra of gold nanoparticles reduced using leaf extract Elephantopus scaber (AuNP-E. scaber $)$ after different microwave irradiations $\left(\lambda_{\max }=538\right.$ $\mathrm{nm})$.

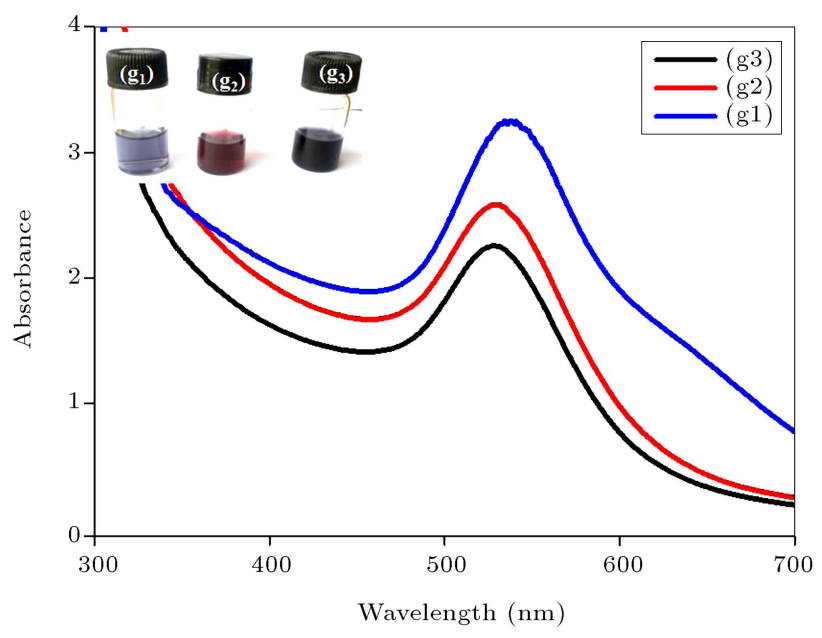

Figure 1(b). Effects of the amount of E. scaber extract on absorption maxima. g1, g2, and g3 represent gold nanoparticles formed from compositions of $9: 1,8: 2$, and $7: 3$, respectively.

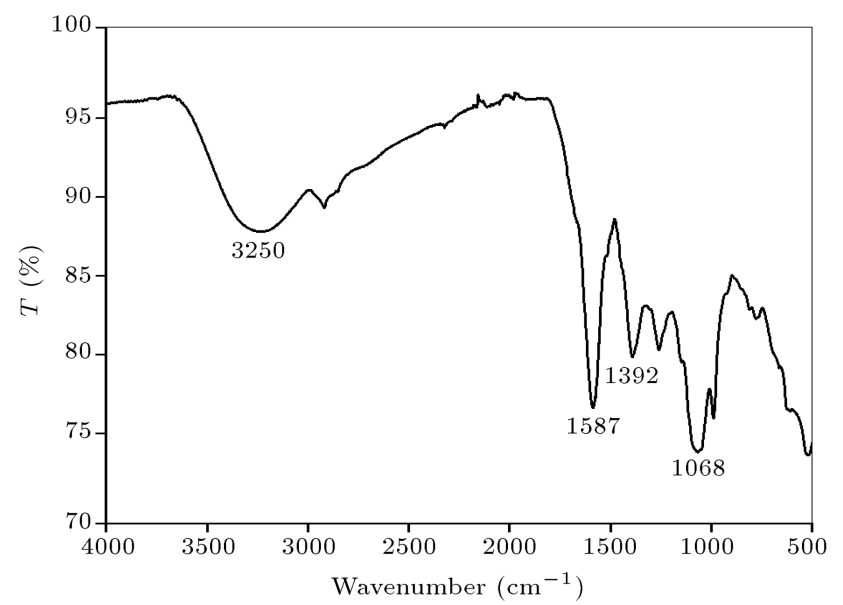

Figure 2. FT-IR spectrum of AuNP-E. scaber.

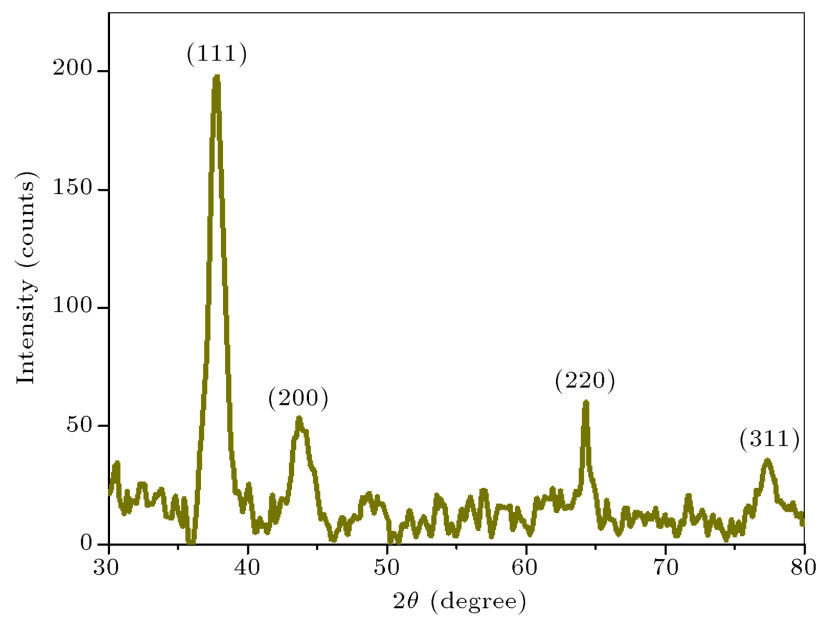

Figure 3. The XRD pattern of AuNP-E. scaber.

FT-IR spectrum of AuNP-E. scaber shows (Figure 2) absorption bands at $3250 \mathrm{~cm}^{-1}, 1587 \mathrm{~cm}^{-1}, 1392$ $\mathrm{cm}^{-1}$, and $1068 \mathrm{~cm}^{-t}$ that resulted from $\mathrm{O}-\mathrm{H},-\mathrm{C}=\mathrm{O}$, $-\mathrm{C}-\mathrm{O}$, and -C-O-C stretching vibrations of aromatic flavonoids and lactones. The bio-reducing agents play the role of surfactants too by excellent capping, as was further proved by TEM analysis.

\subsection{XRD Analysis}

The XRD pattern of AuNP-E. scaber (Figure 3) in the two theta range of $30-80^{\circ}$ was indexed, and peaks at $37.72^{\circ}, 43.7^{\circ}, 64.27^{\circ}$, and $77.37^{\circ}$ came from reflections on Bragg's planes (111), (200), (220), and (311) according to Joint Committee on Powder Diffraction Standards (JCPDS, file no. 04-0784). The powder XRD approved the crystalline dimension of AuNP-E. scaber with an $f c c$ lattice and preferred orientation towards (111) plane.

\subsection{TEM-EDAX characterizations}

Microstructural characterization of AuNP-E. scaber by TEM micrographs (Figure 4) revealed the spherical and triangular shapes of most of the gold nanoparticles. Capping of gold nanoparticles operates through the complexation of biomaterials in the leaf extract and is clearly seen from the TEM images. Microscopic images of AuNP-E. scaber under different image magnifications are observed, and the high-resolution image senses the fringes in the crystalline colloidal gold. SAED pattern displays four circles of bright spots arising from (111), (200), (220), and (311) lattice planes of $f c c$ nanogold. The EDAX spectral pattern has three strong signals approximately at energies 2.3, 8.4, and $9.7 \mathrm{keV}$, confirming the elemental presence of gold [14]. Signals corresponding to copper from the copper grid were used for analysis, and signals of carbon-containing organic moieties of E. scaber were also detected. The size distribution histogram of the particles showed an average size of gold nanopar- 


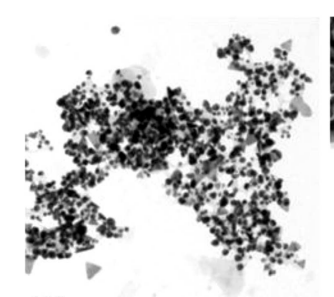

$100 \mathrm{~nm}$

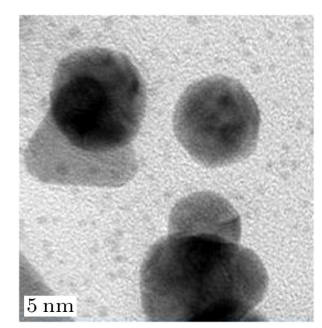

$50 \mathrm{~nm}$
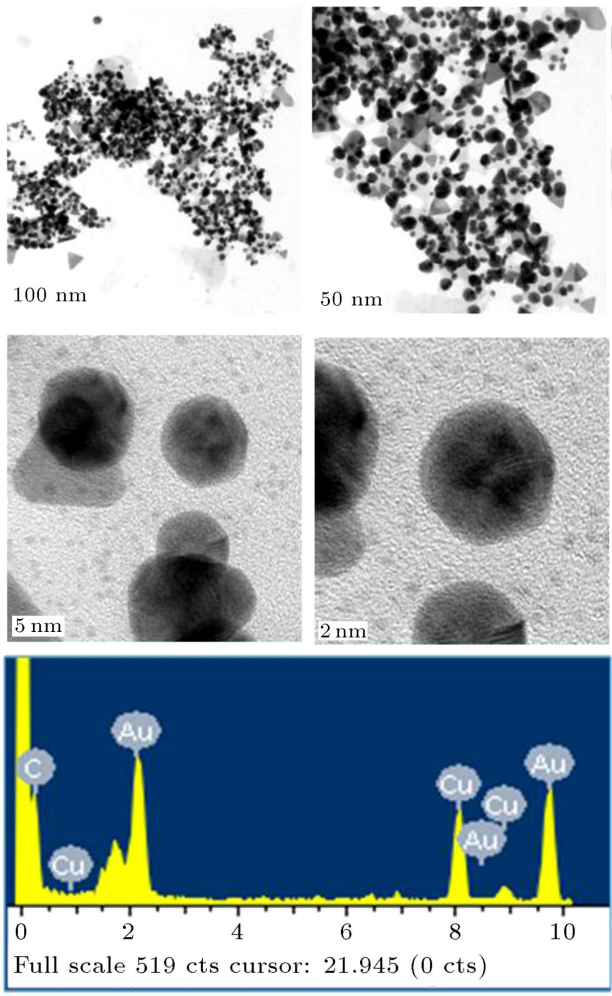
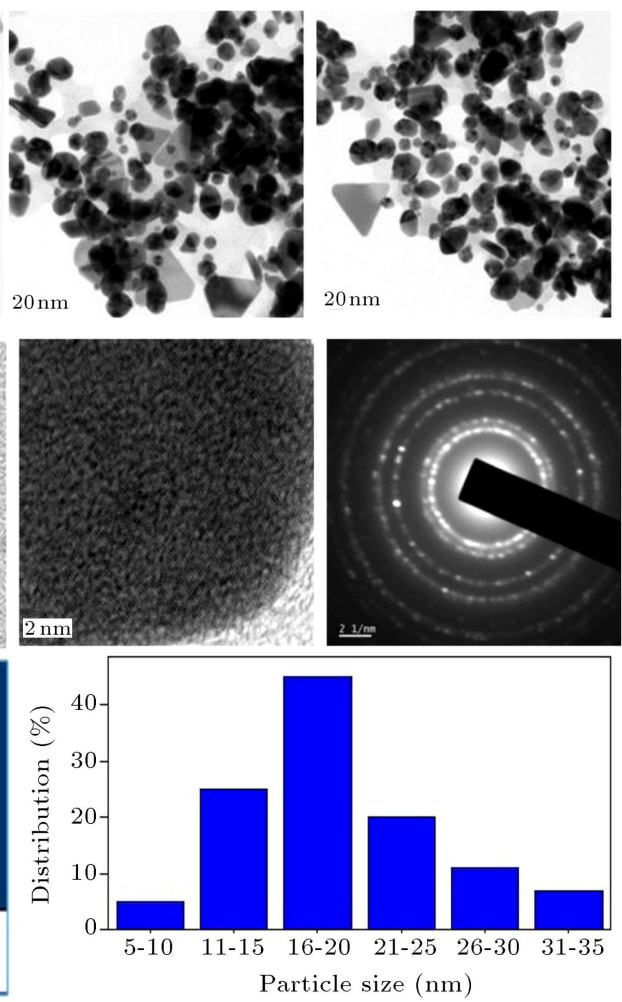

Figure 4. TEM images of AuNP-E. scaber at different magnifications, SAED pattern, EDAX pattern, and particle size histogram.

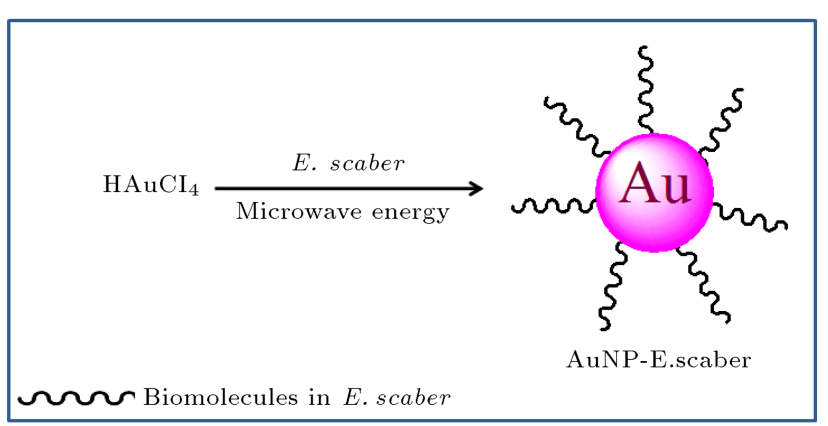

Figure 5. Schematic representation explaining the stability of hard acid - hard base Au(III) complex AuNP-E. scaber.

ticles as $18.97 \pm 5.86 \mathrm{~nm}$. Phytocomponents from E. scaber form a microenvironment around the gold nanoparticles, and the stabilization may be explained by Pearson's concept of the preferential combination of the hard acid $\mathrm{Au}(\mathrm{III})$ and the hard base $-\mathrm{OH}$ groups of phenolic moieties. Further, the electronegativity factor improves the stability of gold complex AuNPE. scaber [1]. The capping phenomenon operated in AuNP-E. scaber by the bio-molecules in the leaf extract can be schematically expressed as in Figure 5 .

\subsection{Dye Degradation catalysis}

Heterocyclic aromatic compounds, such as methyl orange and methylene blue, were the selected compounds for studying catalysis. These are the most common dyes that are used in routine life mainly as indicators in analytical experiments. These intensely colored dyes cannot be decolorized solely by $\mathrm{NaBH}_{4}$ in the absence of a catalyst $[15,16]$. When a small amount $(0.5 \mathrm{ml})$ of AuNP-E. scaber is added to the reaction mixture composed of the respective dye and $\mathrm{NaBH}_{4}$, dangerous dyes suddenly start to degrade due to the incorporation of this electron transfer mediator between the donor $\mathrm{NaBH}_{4}$ and the (acceptor) dye molecules. The plausible mechanism is the Langmuir-Hinshelwood fashion of heterogeneous catalysis [16] owing to the ample surface area provided by AuNP-E. scaber.

The degradation of an azo dye methyl orange $\left(\lambda_{\max }=464 \mathrm{~nm}\right)$ increased significantly by the catalytic presence of AuNP-E. scaber (Figure 6). It is believed that the degradation of this azo dye occurs because of the breaking of $-\mathrm{N}=\mathrm{N}$ - bond, and hydrogenation products include N,N-dimethylbenzene-1,4diamine and sulfanilic acid [16]. $\mathrm{NaBH}_{4}$ functions as a supplier of hydrogen atoms. The reaction progress is monitored by two optical densities: a decrease in the intensity of the peak at $464 \mathrm{~nm}$ and an increase in the intensity of the amino peak around $248 \mathrm{~nm}$, as shown in Figure 6. The rate constant calculated from the slope of $\ln [\mathrm{A}]$ versus time graph of this pseudofirst-order reaction is $0.494 \mathrm{~min}^{-1}$. Thus, the gold nanocatalyst successfully enhanced the degradation 


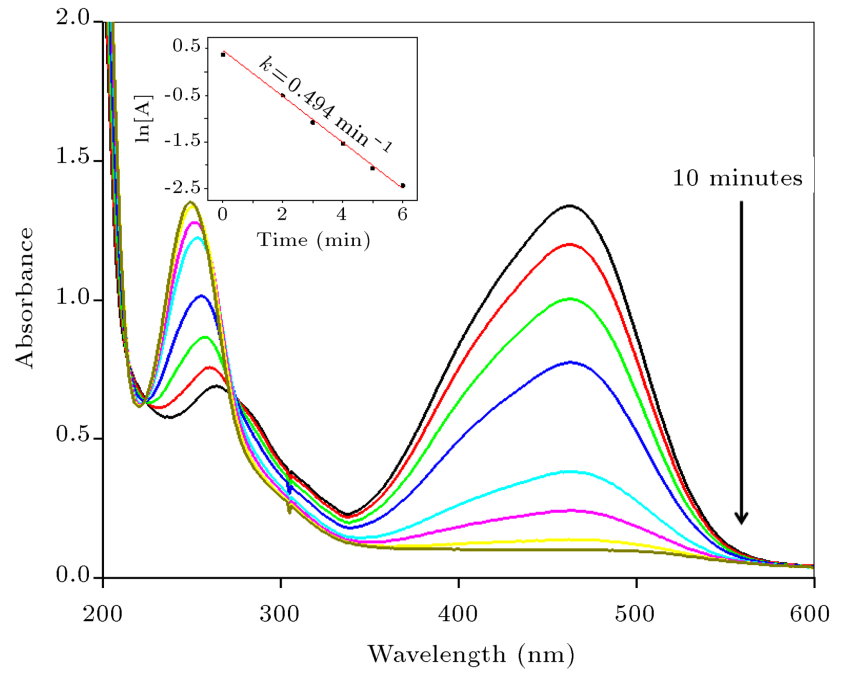

Figure 6. Degradation of methyl orange catalyzed by AuNP-E. scaber $(0.02 \mathrm{mg} / \mathrm{mL})$. Inset shows the kinetic plot of $\ln [\mathrm{A}]$ against time.

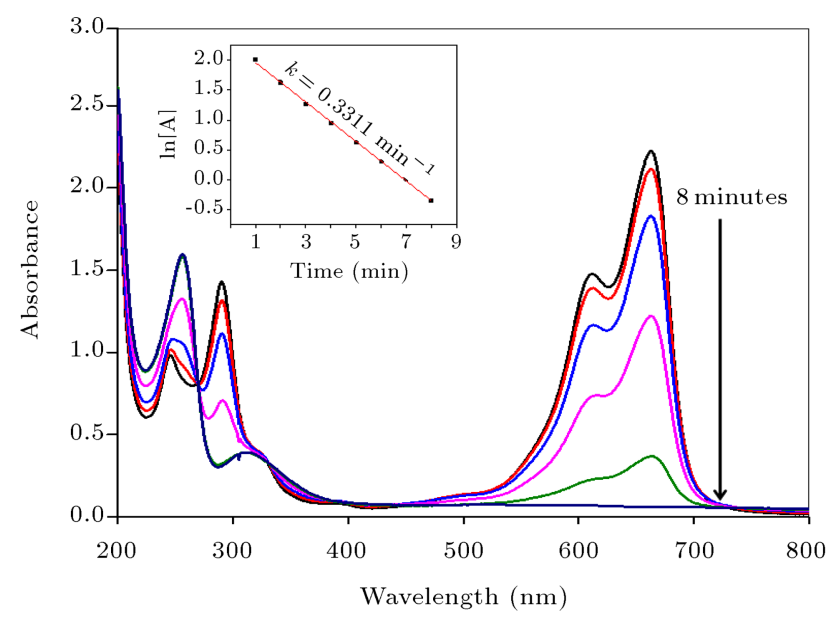

Figure 7. Degradation of methylene blue catalyzed by AuNP-E. scaber $(0.02 \mathrm{mg} / \mathrm{mL})$. Inset shows the kinetic plot of $\ln [\mathrm{A}]$ against time.

of methyl orange in 10 minutes without any light irradiation.

The intensely colored cationic dye, methylene blue, is a threat to wastewater treatments [17]. Effective degradation of methylene blue $\left(\lambda_{\max }=664\right.$ $\mathrm{nm})$ can be achieved by AuNP-E. scaber catalyst. Degradation can be followed by visual observation since the dye has strong blue color when it is in the oxidized form, and the reduced leuco-form has no color. Degradation of MB is systematically done by considering UV-vis. spectra of the reaction mixture with time (as shown in Figure 7). AuNP-E. scaber largely supports the removal of methylene blue almost instantaneously ( 8 minutes). The rate constant for the green catalysis obtained from the slope of the linear plot of $\ln [\mathrm{A}]$ against time is $0.3311 \mathrm{~min}^{-1}$.

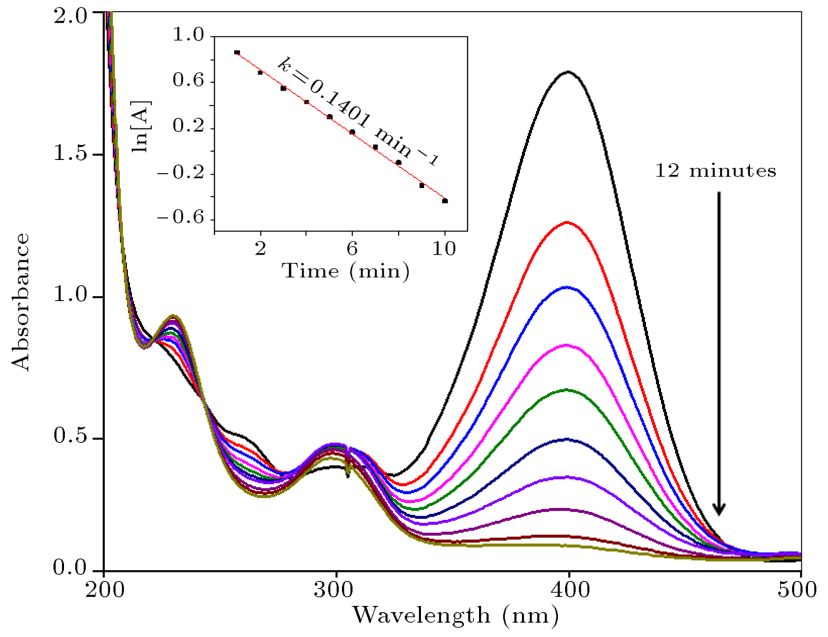

Figure 8. Chemical reduction of 4-nitrophenol to 4-aminophenol catalyzed by AuNP-E. scaber (0.02 $\mathrm{mg} / \mathrm{mL}$ ). Inset shows the kinetic plot of $\ln [\mathrm{A}]$ against time.

\subsection{Reduction of 4-nitrophenol by $\mathrm{NaBH}_{4}$ using the green catalyst, AuNP-E. scaber}

An anthropogenic pollutant 4-nitrophenol can be reduced to another useful chemical 4-aminophenol, which is an important ingredient in the preparation of many analgesics and antipyretics [18]. The reduction of 4-nitrophenol was observed through UV-vis. spectral analysis (Figure 8), and the peak at $400 \mathrm{~nm}$ depleted its intensity as the reduction proceeded [19]. The progress of the reaction was identified by the concomitant growth in the amino peak around $295 \mathrm{~nm}$, and the reduction completed in 12 minutes. The smallsized AuNP-E. scaber promoted adsorption of the reactants on the catalytic surface, and the reduction was explained by Langmuir-Hinshelwood model of heterogeneous catalysis [20]. The kinetic barrier between the electron donor and the acceptor was overcome by the gold nanoparticles of intermediate reduction potential [21]. Pseudo-first-order rate constant was calculated as $0.1404 \mathrm{~min}^{-1}$. The present nanoparticles provided a novel candidate for 4-nitrophenol reduction.

\section{Conclusions}

Synthesis of Elephantopus scaber reduced and microwave supported gold nanoparticles offers an efficient and agile method for large-scale production of gold nanoparticles. The characterization of metal nanoparticles was done by visual observation and most of the world-class instruments such as UV-vis., FTIR, XRD, TEM, and EDAX. The plant reduced gold nanoparticles will surely modify the wastewater management schemes of various dye industries on an economic basis. The chemocatalytic property of the gold nanoparticles in reducing the anthropogenic pollutant 4-nitrophenol to 4-aminophenol can be extended to other organic 
reduction reactions, leading to a 'green revolution' in laboratory experiments.

\section{Acknowledgements}

Authors gratefully acknowledge the financial assistance to Sijo Francis from University Grants Commission (under FDP Scheme of UGC), Government of India.

\section{References}

1. Ahmad, B., Hafeez, N., Bashir, S., Rauf, A., and Ur-Rehman, M. "Phytofabricated gold nanoparticles and their biomedical applications", Biomed. Pharmacother., 89, pp. 414-425 (2017).

2. Francis, S., Joseph, S., Koshy, E.P., and Mathew, B. "Synthesis and characterization of multifunctional gold and silver nanoparticles using leaf extract of: Naregamia alata and their applications in the catalysis and control of mastitis", New J. Chem., 41(23), pp. 14288-14298 (2017).

3. Santhoshkumar, J., Rajeshkumar, S., and Venkat Kumar, S. "Phyto-assisted synthesis, characterization and applications of gold nanoparticles - A review", Biochem. Biophys. Reports, 11, pp. 46-57 (2017).

4. Saha, S., Agasti, S., Kim, C., Li, X., and Rotello, V.M. "Gold nanoparticles in chemical and biological sensing", Chem. Rev., 112(5), pp. 2739-2779 (2012).

5. Hiradeve, S.M. and Rangari, V.D. "Elephantopus scaber Linn.: A review on its ethnomedical, phytochemical and pharmacological profile", J. Appl. Biomed., 12(2), pp. 49-61 ( 2014).

6. Francis, S., Joseph, S., Koshy, E.P., and Mathew, B. "Green synthesis and characterization of gold and silver nanoparticles using Mussaenda glabrata leaf extract and their environmental applications to dye degradation", Environ. Sci. Pollut. Res., 24(21), pp. 17347-17357 (2017).

7. Babu, P.J., Das, R.K., Kumar, A., and Bora, U. "Microwave-mediated synthesis of gold nanoparticles using coconut water", Int. J. Green Nanotechnol., 3(1), pp. 13-21 (2011).

8. Yunpu, W., Leilei, D., Liangliang, F., Shaoqi, S., Yuhuan, L., and Roger, R. "Review of microwaveassisted lignin conversion for renewable fuels and chemicals", J. Anal. Appl. Pyrolysis, 119, pp. 104-113 (2016).

9. Nüchter, M., Ondruschka, B., Bonrath, W., and Gum, A. "Microwave assisted synthesis - a critical technology overview", Green Chem., 6(3), pp. 128-141 (2004).

10. Dutta, P.P., Bordoloi, M., Gogoi, K., Roy, S., Narzary, B., Bhattacharyya, D.R., Mohapatra, P.K., and Mazumder, B. "Antimalarial silver and gold nanoparticles: Green synthesis, characterization and in vitro study", Biomed. Pharmacother., 91, pp. 567580 (2017).

11. Guo, L., Jackman, J.A., Yang, H.-H., Chen, P., Cho, N.-J., and Kim, D.-H. "Strategies for enhancing the sensitivity of plasmonic nanosensors", Nano Today, 10(2), pp. 213-239 (2015).

12. Philip, D. "Rapid green synthesis of spherical gold nanoparticles using Mangifera indica leaf", Spectrochim. Acta-Part A Mol. Biomol. Spectrosc., 77(4), pp. $807-810$ (2010).

13. Rajan, A., Vilas, V., and Philip, D. "Studies on catalytic, antioxidant, antibacterial and anticancer activities of biogenic gold nanoparticles", J. Mol. Liq., 212, pp. 331-339 (2015).

14. Vijayan, R., Joseph, S., and Mathew, B. "Indigoferatinctoria leaf extract mediated green synthesis of silver and gold nanoparticles and assessment of their anticancer, antimicrobial, antioxidant and catalytic properties", Artif. Cells, Nanomedicine, Biotechnol., 46(4), pp. 861-871 (2017).

15. Varadavenkatesan, T., Selvaraj, R., and Vinayagam, R. "Phyto-synthesis of silver nanoparticles from mussaenda erythrophylla leaf extract and their application in catalytic degradation of methyl orange dye", J. Mol. Liq., 221, pp. 1063-1070 (2016).

16. Edison, T.N.J.I., Atchudan, R., Kamal, C., and Lee, Y.R. "Caulerpa racemosa: a marine green alga for eco-friendly synthesis of silver nanoparticles and its catalytic degradation of methylene blue", Bioprocess Biosyst. Eng., 39(9), pp. 1401-1408 (2016).

17. Han, T.H., Khan, M.M., Kalathil, S., Lee, J., and Cho, M.H. "Simultaneous enhancement of methylene blue degradation and power generation in a microbial fuel cell by gold nanoparticles", Ind. Eng. Chem. Res., 52, pp. 8174-8181 (2013).

18. Srisombat, L., Nonkumwong, J., Suwannarat, K., Kuntalue, B., and Ananta, S. "Simple preparation Au/Pd core/shell nanoparticles for 4-nitrophenol reduction", Colloids Surfaces A Physicochem. Eng. Asp., 512, pp. 17-25 (2017).

19. Francis, S., Joseph, S., Koshy, E.P., and Mathew, B. "Microwave assisted green synthesis of silver nanoparticles using leaf extract of elephantopus scaber and its environmental and biological applications", Artif. Cells, Nanomedicine, Biotechnol., 46(4), pp. 795-804 (2017).

20. Manjari, G., Saran, S., Arun, T., Devipriya, S.P., and Vijaya Bhaskara Rao, A. "Facile aglaia elaeagnoidea mediated synthesis of silver and gold nanoparticles: antioxidant and catalysis properties", J. Clust. Sci., 28, pp. 2041-2056 (2017). 
21. Gangula, A., Podila, R., Karanam, R.M.L., Janardhana, C., and Rao, A.M. "Catalytic reduction of 4nitrophenol using biogenic gold and silver nanoparticles derived from Breynia rhamnoides", Langmuir, 27(24), pp. 15268-15274 (2011).

\section{Biographies}

Sijo Francis is an Assistant Professor in Chemistry, St. Joseph's College, Moolamattom. She is doing her $\mathrm{PhD}$ and was a full-time research scholar during 2015-2018 under FDP Scheme of University Grants Commission, Government of India.
Ebey P. Koshy is an Associate Professor and a research guide in Chemistry, St. Joseph's College, Moolamattom. He has more than ten publications in the peer-reviewed international journals.

Beena Mathew is the present Professor and Director of School of Chemical Sciences, Mahatma Gandhi University, Kottayam. Her research areas of interest are self-assembled supramolecular materials, green Chemistry, molecular sensors, and targeted drug delivery. She has more than a hundred publications in the peerreviewed international journals and supervised more than twenty-five PhD students. 